\title{
Risk factors for dental caries in children with developmental disabilities
}

\section{Ana Paula Vasques Sales BRAÚNA(a) Mauro Henrique Nogueira Guimarães de ABREU(a) Vera Lúcia Silva RESENDE(b) Lia Silva de CASTILHO(b)}

(a) Universidade Federal de Minas Gerais - UFMG, Department of Community and Preventive Dentistry, School of Dentistry, Belo Horizonte, MG, Brazil.

(b) Universidade Federal de Minas Gerais - UFMG, Department of Operative Dentistry, School of Dentistry, Belo Horizonte, $M G$, Brazil.

Declaration of Interests: The authors certify that they have no commercial or associative interest that represents a conflict of interest in connection with the manuscript.

\section{Corresponding Author:}

Mauro Henrique Nogueira Guimarães Abreu E-mail: maurohenriqueabreu@gmail.com

DOI: 10.1590/1807-3107BOR-2016.vol30.0079

Submitted: Jul 09, 2015

Accepted for publication: Mar 23, 2016

Last revision: Apr 27, 2016
Abstract: The aim of the present study was to investigate risk factors for dental caries in children with developmental disabilities who were treated at a clinical reference service for patients with special needs in Belo Horizonte, MG, Brazil. This is a retrospective cohort study that evaluated 401 dental charts of individuals without dental caries or restorations in their first dental appointment. The dependent variable was the time of occurrence of new dental caries or restorations and was measured in months. Gender, age, International Code of Diseases (ICD), mother's education, sugar consumption, use of fluoride toothpaste, oral hygiene, mouth breathing, reports of xerostomia, gingival status, use of psychotropic or asthma drugs, and history of asthma were covariates. The Cox proportional hazards regression model was used to estimate the raw and adjusted hazard ratios and their respective 95\% confidence intervals. The average time that individuals remained free of dental caries/restoration was equal to 107.46 months (95\%CI 95.41 to 119.51), with a median of caries-free children up to 94 months. For each point increase in the scale of sucrose consumption, the increase in caries risk was 1.07 (95\%CI 1.01 to 1.15). Sucrose consumption was the only risk factor for dental caries found in this group of individuals with developmental disabilities.

Keywords: Disabled Persons; Dental Caries; Epidemiology.

\section{Introduction}

Dental caries is considered to occur more frequently in individuals with special health care needs. ${ }^{1,2,3,4}$ Dental caries is a multifactor disease in which different individual and contextual factors interact. ${ }^{5}$ The factors associated with dental caries in developmentally disabled children include socioeconomics, living in a community with fluoridated water, ${ }^{3}$ gender, ${ }^{1}$ and oral hygiene. ${ }^{6}$ The risk for dental caries in institutionalized patients with severe motor and intellectual disabilities is highest for those with rumination habits. ${ }^{7}$ However, there is little evidence and few longitudinal studies on the risk for dental caries.

Identifying risk factors for any disease is important when implementing public health strategies for disease control in a population-based approach. ${ }^{8}$ The objective of this study was to investigate the risk factors for dental caries in children with developmental disabilities who were treated in a rehabilitation reference center for patients with neuropsychomotor deficiencies in Belo Horizonte, MG, Brazil. This study tested the hypothesis 
that the risk of dental caries in patients with developmental disabilities increases based on age, gender, the patient's diagnosis, maternal education level, sucrose intake index, use of fluoride toothpaste, oral hygiene, mouth breathing, xerostomia, gingival changes, use of psychotropic drugs, use of drugs for asthma treatment, and previous history of asthma.

\section{Methodology}

The study was submitted to and approved by the Ethics Committee for Human Research of the Federal University of Minas Gerais (protocol \# ETIC 219/03).

This was a retrospective cohort study based on information obtained from the medical records of a reference center for people with developmental disabilities. Data were collected from the beginning of this dental service in 1998 to the time of data collection in 2014. All patients who received dental treatment and maintenance were eligible for the study, including one patient who was fed by tube. Patients with any cavitated dentin carious lesions or restorations at the first dental examination were excluded from this study. A total of 517 dental records were examined, and 401 patients were included in the study.

One trained researcher (Cohen Kappa=1.0) was in charge of collecting information from the records. A database was created in Excel for Windows (Microsoft, Redmond, WA, USA) and checked by a second experienced researcher who had been working in dental care for people with special needs for 17 years.

The dependent variable was the time of occurrence (in months) of cavitated dentin carious lesions or the presence of a new restoration, according to WHO criteria. ${ }^{9}$ It is very difficult to assess early caries activity in this group of patients due to involuntary movements of the tongue and also because of the difficulty in maintaining a dry field for the diagnosis of early carious lesions. Radiographic exams were not performed due to patients' involuntary movements, cognitive impairments and high degrees of spasticity. Therefore, cavitated dentin lesions are more easily and accurately detected in this group. ${ }^{10,11,12,13}$

Missing deciduous teeth were not included due to the impossibility of determining whether the loss was from natural exfoliation or decay. The follow-up of each patient ranged from 1 to 184 months.
The following covariates were collected: age (years); gender (male or female); diagnosis of the patient according to the International Classification of Diseases (ICD) (G80: Cerebral Palsy group or other diagnoses); ${ }^{14,15}$ maternal education (less than 8 years or more than 8 years of formal schooling); sucrose intake index, ${ }^{16}$ use of fluoride toothpaste (yes or no); oral hygiene (good, fair or poor), ${ }^{17}$ mouth breathing (yes or no); ${ }^{15}$ gingival changes in color and contour (yes or no), ${ }^{18}$ use of psychotropic drugs (yes or no); use of drugs for asthma treatment (yes or no), ${ }_{i}^{19}$ previous history of asthma (yes or no); and parents' or care givers' reports about patients' xerostomia (yes or no).

Parents and caregivers were encouraged to record all food the patient ate at each meal. We assigned a weight of " 1 " to liquids with sucrose and a weight of " 2 " to sticky foods with sucrose. If sucrose was ingested during breakfast, lunch or dinner, the weight was " 1 ". For ingestion between the principal meals, the weight was " 2 ". For each contact with food containing sucrose, we multiplied the consistency (liquid or sticky) by the moment (during or between the principal meals). For example, if a parent recorded that his/her son ate a piece of a cake during breakfast, we multiplied " 2 " (sticky food with sucrose) by "1" (during a principal meal), and this specific meal contributed 2 points to the scale. Each day, we totaled the values obtained by each contact with food containing sucrose. ${ }^{16}$

All patients at this center had a dental appointment every six months. In a few cases, this period might be exceeded due to cancelled appointments at the request of the patient.

The statistical analysis involved three steps. Initially, a description of all variables was performed by calculating the ratios and measures of central tendency and variability. In the second step, the Kaplan-Meier method was used to estimate the average time (95\% confidence interval (CI)) and median survival time (i.e., how long the patient was free from cavitated dentine carious lesions or restorations). A survival graph was drawn. Finally, a Cox proportional hazard model that was adjusted for covariates was used to estimate the crude and adjusted hazard ratios (HR with $95 \% \mathrm{CI}$ ) of cavitated dentin lesions or restorations. Each covariate was 
included separately in the Cox model, and crude HRs $(95 \% \mathrm{CI})$ and $\mathrm{p}$-values were estimated. Covariates with p-values less than 0.25 were included in the final Cox model, and only those with a p-value of less than 0.05 were retained. The variable selection method in the final Cox model was the forward stepwise (Wald). Patients' missed dental appointments for any reason (treatment abandonment, death) as well as the presence of cavitated dentin carious lesions and/or new restorations at the end of the monitoring period were censored. The "event" was the presence of a cavitated dentin carious lesions or a new restoration. All statistical analyses were performed using SPSS software for Windows, version 21.0 (SPSS Inc., Chicago, USA).

\section{Results}

The mean age of subjects in the first query was 3.4 years with a median of 2 years and a range of 0 to 22 years. The sucrose intake index ranged from 0 to 18 with a median of 8 . Most (56.9\%) patients were male. Other sociodemographic and clinical characteristics are shown in Table 1. The patients had different diagnoses, including G800 (spastic

Table 1. Clinical and sociodemographic characteristics of patients with developmental disabilities, Belo Horizonte, Brazil, 1998 to 2014.

\begin{tabular}{lc}
\hline Variables & $\mathrm{N}(\%)$ \\
\hline Male gender $(\mathrm{n}=401)$ & $228(56.9)$ \\
Mother formal scholarship up to 8 years $(\mathrm{n}=313)$ & $87(27.3)$ \\
Use of fluoride toothpaste $(\mathrm{n}=100)$ & $64(64.0)$ \\
Oral hygiene $(\mathrm{n}=372)$ & \\
$\quad$ Good & $316(84.9)$ \\
Fair & $51(13.7)$ \\
$\quad$ Poor & $5(1.3)$ \\
ICD G800 diagnoses $(\mathrm{n}=293)$ & $233(79.5)$ \\
Mouth breathing $(\mathrm{n}=398)$ & $186(46.7)$ \\
Xerostomia ( $\mathrm{n}=395)$ & $53(13.4)$ \\
Gingivitis $(\mathrm{n}=366)$ & $53(14.5)$ \\
Use of psychotropic drugs $(\mathrm{n}=395)$ & $197(49.9)$ \\
Use of drugs for asthma treatment $(\mathrm{n}=394)$ & $32(8.1)$ \\
Previous history of asthma $(\mathrm{n}=351)$ & $19(5.4)$ \\
\hline
\end{tabular}

ICD: International code of diseases. quadriplegic cerebral palsy), G801 (spastic diplegic cerebral palsy), G802 (spastic hemiplegic cerebral palsy), G811 (spastic hemiplegia), G824 (spastic tetraplegia), F82 (specific developmental disorder of motor function), G540 (brachial plexus disorders), G71 (primary disorders of muscles), M401 (other secondary kyphosis), P271 (bronchopulmonary dysplasia), P143 (other brachial plexus injuries), Q052 (lumbar spina bifida with hydrocephalus), Q053 (sacral spina bifida with hydrocephalus), Q057 (lumbar spina bifida without hydrocephalus), Q059 (spina bifida unspecified), Q90 (Down syndrome), R628 (other lack of expected normal physiological development) and R629 (lack of expected normal physiological development unspecified).

The average time that individuals remained free of cavitated dentin carious lesions or restorations was 107.46 months (95\%CI, 95.41 to 119.51) with median of 94 months (Figure 1).

The only covariate associated with an increased risk for caries was the sucrose intake index $(p=0.035)$. Other variables with $p \leq 0.25$, such as the use of psychotropic drugs, the use of drugs for asthma treatment and age, were not retained in the final model. For each increased point in the scale of sucrose consumption, there was a 1.07 increase in the risk for caries (95\%CI, 1.01 to 1.15) (Table 2).

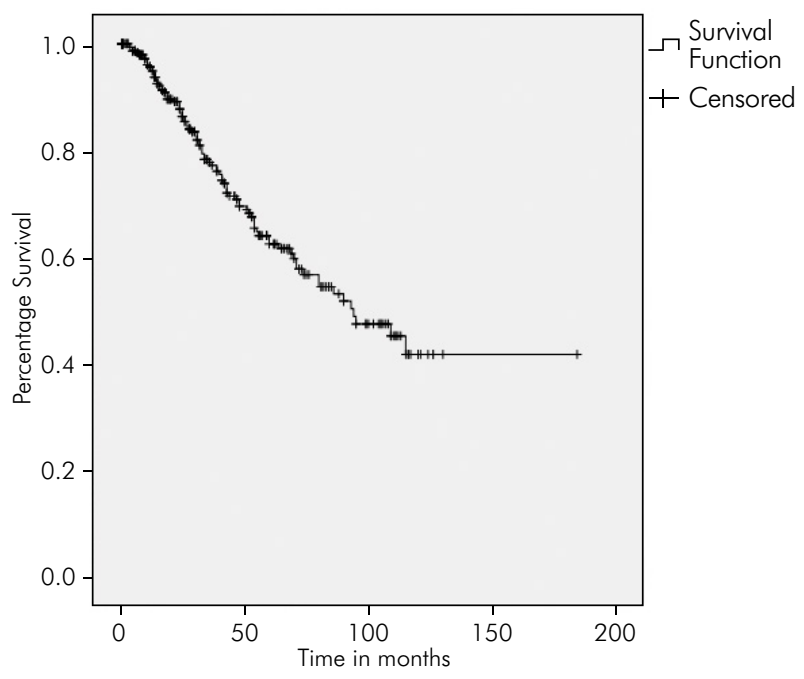

Figure. Survival function of being free of cavitated dentin carious lesion and/or restorations among patients with developmental disabilities, Belo Horizonte, Brazil, 1998 to 2014. 
Risk factors for dental caries in children with developmental disabilities

Table 2. Risk factors for dental caries among patients with developmental disabilities, Belo Horizonte, Brazil, 1998 to 2014.

\begin{tabular}{|c|c|c|c|c|}
\hline Variables & Crude HR $(95 \% \mathrm{Cl})$ & $p$-value & Final model HR $(95 \% \mathrm{Cl})$ & $\mathrm{p}$-value \\
\hline Age (in years) & $0.93(0.86-1.01)$ & 0.084 & - & - \\
\hline Sucrose intake index & 1.07 (1.01-1.15) & 0.035 & $1.07(1.01-1.15)$ & 0.035 \\
\hline \multicolumn{5}{|c|}{ Use of psychotropic drugs } \\
\hline Yes & $1.53(1.01-1.34)$ & \multirow{2}{*}{0.046} & - & - \\
\hline No & 1 & & - & - \\
\hline \multicolumn{5}{|c|}{ Use of drugs for asthma treatment } \\
\hline Yes & $1.86(0.81-4.28)$ & \multirow{2}{*}{0.142} & - & - \\
\hline No & 1 & & - & - \\
\hline \multicolumn{5}{|c|}{ Previous history of asthma } \\
\hline Yes & $1.46(0.46-4.62)$ & \multirow{2}{*}{0.518} & - & - \\
\hline No & 1 & & - & - \\
\hline \multicolumn{5}{|l|}{ ICD diagnoses } \\
\hline Others & 1 & \multirow{2}{*}{0.430} & - & - \\
\hline G80 & $1.27(0.69-2.34)$ & & - & - \\
\hline \multicolumn{5}{|l|}{ Gender } \\
\hline Male & 1 & \multirow{2}{*}{0.880} & - & - \\
\hline Female & $0.97(0.63-1.47)$ & & - & - \\
\hline \multicolumn{5}{|c|}{ Mother formal scholarship } \\
\hline Up to 8 years & $0.97(0.91-1.04)$ & \multirow{2}{*}{0.468} & - & - \\
\hline More than 8 years & 1 & & - & - \\
\hline \multicolumn{5}{|c|}{ Use of fluoride toothpaste } \\
\hline Yes & $0.65(0.22-1.91)$ & \multirow{2}{*}{0.443} & - & - \\
\hline No & 1 & & - & - \\
\hline \multicolumn{5}{|l|}{ Oral hygiene } \\
\hline Good & $0.94(0.51-1.74)$ & \multirow{2}{*}{0.861} & - & - \\
\hline Fair/poor & 1 & & - & - \\
\hline \multicolumn{5}{|l|}{ Mouth breathing } \\
\hline Yes & 1.21 (0.79-1.85) & \multirow{2}{*}{0.361} & - & - \\
\hline No & 1 & & - & - \\
\hline \multicolumn{5}{|l|}{ Xerostomia } \\
\hline Yes & $1.65(0.42-6.26)$ & \multirow{2}{*}{0.456} & - & - \\
\hline No & 1 & & - & - \\
\hline \multicolumn{5}{|l|}{ Gingivitis } \\
\hline Yes & $0.73(0.39-1.35)$ & \multirow{2}{*}{0.319} & - & - \\
\hline No & 1 & & - & - \\
\hline
\end{tabular}

\section{Discussion}

This study found that sucrose consumption was the independent variable associated with the risk of caries in the studied patients.

This oral health service provides an orientation to dental care for patients and their parents and caregivers, intensive training for home biofilm control, and professional early non-operative intervention. The home care involves careful brushing and the use of fluoride toothpaste. We considered parents' and caregivers' focus on oral hygiene to be very important because of the low average age and high motor 
difficulties of this group of patients. Professional plaque removal during regular consultations serves three purposes: to determine the patient's current state of dental caries activity; to halt the progression of clinical and sub-clinical lesions (if lesions are already visible); and to create a basis for education for both parents and patient. Four aspects should be considered when scheduling the next visit (which, in the case of this extension project, should not exceed 6 months): the cooperation of parents and patients, caries progression, the stage of molar eruption, and caries progression in the occlusal surface of molars. ${ }^{20,21}$ It would be very difficult for the researchers who developed this oral healthcare system ${ }^{21}$ to limit the consumption of fermentable carbohydrates by children and adolescents. Therefore, the main focus is on home biofilm control, including professional intervention in areas of greater biofilm stagnation (first and second permanent molars in eruption). ${ }^{21}$ This assertion should be reviewed by the dental team for patients with disabilities, particularly in view of the identified risk factors. In addition, it is important to review the limits of the actions offered to patients in this clinic ${ }^{8}$, particularly those in this studied group. These children and their families live in contexts that may hinder adherence to habits that are generally considered healthy. The social and behavioral determinants of context may be important to the manifestation of caries ${ }^{5}$ and may surpass the intervention capacity of this service.

The role of a diet rich in sucrose in the development of tooth decay has been discussed and studied extensively. The cultural component of sugar intake is a topic of interest. Mothers who have a cariogenic diet often tend to introduce this same habit to their children, which results in a higher incidence of tooth decay. ${ }^{22} \mathrm{~A}$ diet rich in sucrose and cooked starches, which are highly fermentable and sticky, is also an important factor in the development of dental caries. ${ }^{23}$ The intake of sweetened fruit juices is also associated with dental caries development among young people. ${ }^{24}$ The frequency of sucrose intake is also significantly related to the occurrence of the event. ${ }^{25}$ People with disabilities who are fed by tube have a lower risk of developing caries ${ }^{7}$ because food that is rich in sucrose does not have any contact with the surface of the teeth. In our study, only one patient was fed by tube and therefore had no contact with food containing sucrose in the oral cavity.

The role of diet, however, is not always clear in cross-sectional studies with children with disabilities. In a specific study of Chinese children with intellectual disabilities, a frequent intake of snacks and sweet foods before bedtime did not influence the incidence of caries. ${ }^{26}$

The variables of female gender, ${ }^{27}$ xerostomia, ${ }^{28}$ psychotropic medication, ${ }^{29}$ asthma medication, ${ }^{19}$ mother's level of education, ${ }^{22}$ mouth breathing, ${ }^{30}$ diagnosis, ${ }^{31}$ presence of gengivitis ${ }^{32}$ and use of fluoride toothpaste ${ }^{33}$ were not risk factors for caries in this retrospective cohort study. The probable explanation for the lack of association in our study is the difference in epidemiological methods and statistical analyses of these previous studies. ${ }^{19,22,27,28,29,30,31,32,33}$

Drugs with anticholinergic agents, such as antidepressants, antipsychotics, and anti-parkinsonian drugs, reduce the volume of serous saliva. ${ }^{34}$ Anticonvulsants drugs were the most frequent type of medication used by the patients in this study. We expected that these drugs could be associated with dental caries, as described in a study by Xavier et al., ${ }^{29}$ because sugar and acids are in their formulations (particularly pediatric formulations). However, the use of psychotropic drugs was not significant in the final Cox model.

This study has limitations that have already been mentioned in a previous cross-sectional study. ${ }^{6}$ Data were obtained from dental records with the main goal of developing the patient's treatment plan. These secondary data were obtained from medical records, and the diagnoses of dental caries were made by students under the supervision of their professors as a teaching/learning activity during the dental course. This diagnosis has an initial purpose of helping to plan dental treatment. Although it is not possible to have total control over secondary data obtained from outpatient and hospital records, these data can be of great help in understanding the health/disease process in a population. However, the development of these records was guided by the same professional (an associate professor in the School of Dentistry) of this dental service throughout 
the study period. In addition, these data should not be generalized to the general population of patients with developmental disabilities.

All evaluated factors were collected the first time that the patient used the dental service and may have been modified over time. Therefore, some factors may differ from those found in the initial examination. Furthermore, some variables, such as dietary habits, are difficult to modify. ${ }^{20}$ Finally, other variables that are considered risk factors for dental caries, such as social and contextual determinants, were not available in the medical records and could not be evaluated. ${ }^{5}$

\section{References}

1. Pezzementi ML, Fisher MA. Oral health status of people with intellectual disabilities in the southeastern United States. J Am Dent Assoc. 2005;136(7):903-12. doi:10.14219/jada.archive.2005.0291

2. Morgan JP, Minihan PM, Stark PC, Finkelman MD, Yantsides KE, Park A et al. The oral health status of 4,732 adults with intellectual and developmental disabilities. J Am Dent Assoc. 2012;143(8):838-46. doi:10.14219/jada.archive.2012.0288

3. Chi DL, Rossitch KC, Beeles EM. Developmental delays and dental caries in low-income preschoolers in the USA: a pilot cross-sectional study and preliminary explanatory model. BMC Oral Health. 2013;13:53. doi:10.1186/1472-6831-13-53

4. Oliveira JS, Prado Júnior RR, Sousa Lima KR, Oliveira Amaral H, Moita Neto JM, Mendes RF. Intellectual disability and impact on oral health: a paired study. Spec Care Dentist. 2013;33(6):262-8. doi:10.1111/scd.12015

5. Holst D. Causes and prevention of dental caries: a perspective on cases and incidence. Oral Health Prev Dent. 2005;3(1):9-14. doi:10.3290/j.ohpd.a10070

6. Roberto LL, Machado MG, Resende VL, Castilho LS, Abreu $\mathrm{MH}$. Factors associated with dental caries in the primary dentition of children with cerebral palsy. Braz Oral Res. 2012;26(5):471-7. doi:10.1590/S1806-83242012005000018

7. Idaira Y, Nomura Y, Tamaki Y, Katsumura S, Kodama S, Kurata K et al. Factors affecting the oral condition of patients with severe motor and intellectual disabilities. Oral Dis. 2008;14(5):435-9. doi:10.1111/j.1601-0825.2007.01397.x

8. Rose G. Sick individuals and sick populations. 1985. Bull World Health Organ. 2001;79(10):990-6.

9. World Health Organization. Oral health surveys: basic methods. 5th ed. Geneva: World Health Organization; 2013.
Despite the limitations of this study, we believe that it is one of the few studies with a methodology that enables the estimation of risk factors for decay in patients with special needs. The results presented here can help dentists who work with this patient group to establish strategic actions, particularly in relation to health education and dietary guidance, to achieve better oral health in patients with special needs.

\section{Conclusion}

Sucrose consumption was the only risk factor for dental caries found in this group of individuals with developmental disabilities.

10. Altun C, Guven G, Akgun OM, Akkurt MD, Basak F, Akbulut E. Oral health status of disabled individuals attending special schools. Eur J Dentistry. 2010;4(4):361-6.

11. Jaber MA. Dental caries experience, oral health status and treatment needs of dental patients with autism. J Appl Oral Sci. 2011;19(3):212-7. doi:10.1590/S1678-77572011000300006

12. Sagheri D, McLoughlin J, Nunn JH. Dental caries experience and barriers to care in young children with disabilities in Ireland. Quintessence Int. 2013;44(2):159-69. doi:10.3290/j.qi.a28927

13. Oda Y, Hayashi F, Okada M. Longitudinal study of dental caries incidence associated with Streptococcus mutans and Streptococcus sobrinus in patients with intellectual disabilities. BMC Oral Health. 2015;15(1):102. doi:10.1186/s12903-015-0087-6

14. Centers for Disease Control and Prevention. International classification of diseases, tenth revision, clinical modification (ICD-10-CM). Atlanta: Centers for Disease Control and Prevention; 2015 [cited 2 Feb 2016]. Available at http://www.cdc.gov/nchs/icd/icd10cm.htm

15. Souza VA, Abreu MH, Resende VL, Castilho LS. Factors associated with bruxism in children with developmental disabilities. Braz Oral Res. 2015;29(1):1-5. doi:10.1590/1807-3107BOR-2015.vol29.0009

16. Auad SM, Pordeus IA. Uma proposta para avaliação e aconselhamento dietéticos. Rev CROMG. 2000;6(3):132-8.

17. Greene JC, Vermillion JR. The simplified oral hygiene index. J Am Dent Assoc. 1964;68(1):7-13. doi:10.14219/jada.archive.1964.0034

18. Bonanato K, Paiva SM, Pordeus IA, Ramos-Jorge ML, Barbabela D, Allison PJ. Relationship between mothers' sense of coherence and oral health status of preschool children. Caries Res. 2009;43(2):103-9. doi:10.1159/000209342 
19. Stensson M, Wendt LK, Koch G, Oldaeus G, Lingström P, Birkhed D. Caries prevalence, caries-related factors and plaque $\mathrm{pH}$ in adolescents with long-term asthma. Caries Res. 2010;44(6):540-6. doi:10.1159/000321566

20. Ekstrand KR, Christiansen MEC. Outcomes of a Non-Operative Caries Treatment Programme for Children and Adolescents. Caries Res. 2005;39(6):455-67. doi:10.1159/000088180

21. Meyer K, Khorshidi-Böhm M, Geurtsen W, Günay H. An early oral health care program starting during pregnancy: a long-term study: phase V. Clin Oral Investig. 2014;18(3):863-72. doi:10.1007/s00784-013-1059-3

22. Wigen TI, Wang NJ. Maternal health and lifestyle, and caries experience in preschool children. A longitudinal study from pregnancy to age 5 yr. Eur J Oral Sci. 2011;119(6):463-8. doi:10.1111/j.1600-0722.2011.00862.x

23. Bradshaw DJ, Lynch RJM. Diet and the microbial aetiology of dental caries: new paradigms. Int Dent J. 2013;63 Suppl 2:64-72. doi:10.1111/idj.12082

24. Huew R, Waterhouse P, Moynihan P, Kometa S, Maguire A. Dental caries and its association with diet and dental erosion in Libyan schoolchildren. Int J Paediatr Dent. 2012;22(1):68-76. doi:10.1111/j.1365-263X.2011.01170.x

25. Sheiham A, James WPT. A reappraisal of the quantitative relationship between sugar intake and dental caries: the need for new criteria for developing goals for sugar intake. BMC Public Health. 2014;14(1):863. doi:10.1186/1471-2458-14-863

26. Liu Z, Yu D, Luo W, Yang J, Lu J, Gao S et al. Impact of oral health behaviors on dental caries in children with intellectual disabilities in Guangzhou, China. Int J Environ Res Public Health. 2014;11(10):11015-27. doi:10.3390/ijerph111011015
27. Martinez-Mier EA, Zandona AF. The impact of gender on caries prevalence and risk assessment. Dent Clin North Am. 2013;57(2):301-15. doi:10.1016/j.cden.2013.01.001

28. Flink H, Tegelberg A, Arnetz J, Birkhed D. Correlation between perceived experience of caries disease and recorded caries activity among adult patients at a Swedish public dental clinic: a longitudinal study. Acta Odontol Scand. 2013;71(6):1486-92. doi:10.3109/00016357.2013.771406

29. Xavier AF, Moura EFF, Azevedo WF, Vieira FF, Abreu MHN, Cavalcanti AL. Erosive and cariogenicity potential of pediatric drugs: study of physicochemical parameters. BMC Oral Health. 2013;13(1):71-84. doi:10.1186/1472-6831-13-71

30. Nascimento Filho E, Mayer MPA, Pontes P, Pignatari ACC, Weckx LL. Caries prevalence, levels of mutans streptococci, and gingival and plaque indices in 3.0- to 5.0-year-old mouth breathing children. Caries Res. 2004;38(6):572-5. doi:10.1159/000080589

31. Santos MTBR, Guare RO, Celiberti P, Siqueira WL. Caries experience in individuals with cerebral palsy in relation to oromotor dysfunction and dietary consistency. Spec Care Dentist. 2009;29(5):198-203. doi:10.1111/j.1754-4505.2009.00092.x

32. Cortellazzi KL, Pereira SM, Tagliaferro EP, Ambrosano GM, Zanin L, Meneghim MC et al. Risk indicators of gingivitis in 5-year-old brazilian children. Oral Health Prev Dent. 2008;6(2):131-7.

33. Cury JA, Tenuta LMA. Evidence-based recommendation on toothpaste use. Braz Oral Res. 2014;28(Spec Issue):1-7. doi:10.1590/S1806-83242014.50000001

34. Vinayak V, Annigeri RG, Patel HA, Mittal S. Adverse effects $\mathrm{f}$ drugs on saliva and salivary glands. J Orofac Sci. 2013;5(1):15-20. doi:10.4103/0975-8844.113684 